\title{
The Antihypertensive Efficacy and Safety of Catheter- Based Renal Denervation: A Report of 2 Cases
}

\author{
Liying Gong ${ }^{1,2}$, Fenling Jiang ${ }^{1}$ and Guoping Yang*2 \\ ${ }^{1}$ Department of Cardiology, China \\ ${ }^{2}$ Department of Clinical Pharmacology, China \\ *Corresponding author: Guoping Yang, Department of Clinical Pharmacology, Changsha Hunan, China
}

\begin{abstract}
ARTICLE INFO
Received: 幽 February 26, 2019

Published: March 08, 2019

Citation: Liying G, Fenling J, Guoping Y. The Antihypertensive Efficacy and Safety of Catheter-Based Renal Denervation: A Report of 2 Cases. Biomed J Sci \& Tech Res 15(4)-2019. BJSTR. MS.ID.002737.
\end{abstract}

Keywords: Catheter-Based Renal Denervatio; Resistance Hypertension; Long Follow-Up Period; Efficacy and Safety

\begin{abstract}
The renal sympathetic nervous system has a decisive role in the induction and maintenance of hypertension [1]. The inhibition of sympathetic overactivity is considered an important target for the treatment of hypertension and its complications. Catheter-based renal denervation (RDN) has emerged as an innovative interventional approach to reduce blood pressure (BP) in patients with resistance hypertension [2-4]. This technique delivers low-level radiofrequency energy throughout the renal artery wall and selective destruction renal nerves and thereby decrease BP. Both the Symplicity HTN-1 trial and Symplicity HTN2 trial significant reduction of BP following RDN $[4,5]$. However, the Symplicity HTN-3 study did not show effective BP reduction [6]. So, we reported 2 cases of resistance hypertension patients with a long follow-up time of over 6 years to preliminarily investigate the efficacy and safety of RDN.
\end{abstract}

\section{Patient information}

\section{Case 1}

The patient was a 49-year-old male. The patient was admitted to the hospital because he had suffered recurring dizziness and headache for more than 10 years and aggravated symptoms for 3 days. The patient had a history of hypertension for more than 10 years; during this period, the highest blood pressure reached $180 / 110 \mathrm{mmHg}$. The patient had undergone the long-term use of 3-4 types of antihypertensive agents (including diuretic agents) to control blood pressure; however, his blood pressure still fluctuated between 150-170/90-100mmHg.The blood pressure on admission was $160 / 100 \mathrm{mmHg}$ (after taking medications). After complete examinations, secondary hypertension was excluded. The oral glucose tolerance test (OGTT) results at $0 \mathrm{~min}$ and $120 \mathrm{~min}$ were $6.47 \mathrm{mmol} / \mathrm{L}$ and $9.68 \mathrm{mmol} / \mathrm{L}$, respectively. Echocardiography showed double atrial enlargement and left ventricular hypertrophy. The diagnoses were

i. Hypertension (stage 2, very high risk) and heart enlargement ii. Impaired glucose tolerance.

After admission, the patient received perindopril 8mg/day, amlodipine $5 \mathrm{mg}$ /day, indapamide sustained-release tablets $1.5 \mathrm{mg} /$ day, and arotinolol $5 \mathrm{mg} /$ twice a day as a quadruple antihypertensive combination. Blood pressure monitoring showed that his blood pressure fluctuated between 142-150/90-96mmHg.

This middle-aged male patient had hypertension combined with left ventricular hypertrophy and also had impaired glucose tolerance. After receiving 4 types of antihypertensive agents, the blood pressure still did not reach the goal, which met the diagnostic criteria for resistant hypertension. There were indications of RDN, and the patient was willing to undergo surgery; therefore, RDN was performed on January $5^{\text {th }}, 2012$ and proceeded smoothly. After the surgery, the antihypertensive agents were reduced to perindopril $4 \mathrm{mg}$ /day and amlodipine $5 \mathrm{mg} /$ day, and blood pressure was controlled between 120-130/82-86mmHg. Strict follow-up was conducted after surgery, and the symptoms of headache and dizziness improved compared with the symptoms before surgery. 
There was no hematuria or lower back pain. On June $17^{\text {th }}, 2012$, routine urine tests and renal function tests were normal, and renal artery imaging showed that no renal arterial stenosis (Figure 1). BP monitor, a urine tests and renal function tests every 12-month during the 6 years of follow-up is mandatory. The BP and creatinine clearance (CCr) result as show in Figure 2. There were no significant changes in SBP, DBP, and CCr after RDN in the long follow-up period.

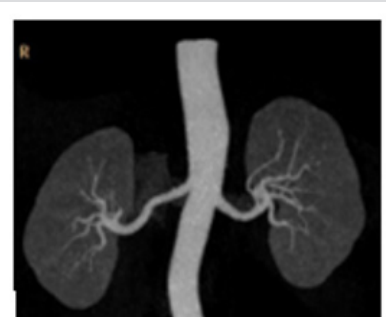

A

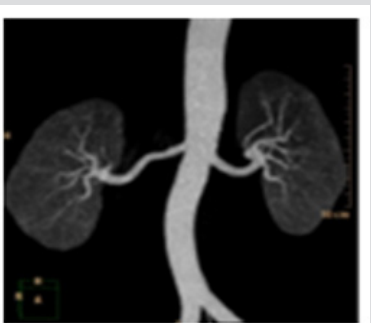

B a) Before surgery

b) 6-month post-surgery

Figure 1: The renal artery imaging of case 1.

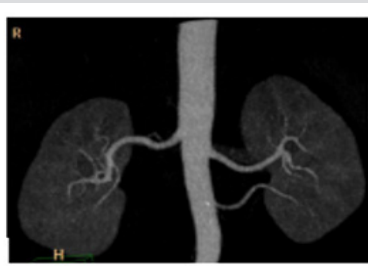

C

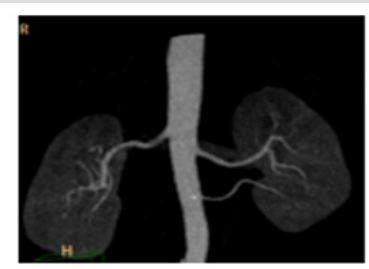

D c) Before surgery

d) 6-month post-surgery

Figure 1: The renal artery imaging of case 2.

\section{Case 2}

The patient was a 45-year-old male. The patient was admitted to the hospital due to elevated blood pressure for 6 years and exertional dyspnea for 1 year. The patient had hypertension for 6 years, and the highest pressure reached $170 / 110 \mathrm{mmHg}$. The patient usually took several types of antihypertensive agents (including angiotensin-converting enzyme inhibitors (ACEIs), diuretic agents, and $\beta$-receptor blockers), and his blood pressure was controlled between 150-160/90-110mmHg. His blood pressure on admission was 160/110mmHg (after taking medications). Secondary hypertension was excluded after the completion of related examinations. After admission, the patient received perindopril $8 \mathrm{mg}$ /day, amlodipine $5 \mathrm{mg} /$ day, and indapamide sustained-release tablets $1.5 \mathrm{mg}$ /day as an antihypertensive combination. In addition, the patient received furosemide on the following day to reduce the cardiac preload. The blood pressure fluctuated between 150156/90-98mmHg. The diagnoses were hypertension (stage 3, very high risk), heart enlargement, and class III cardiac function. This patient was a middle-aged male with an obese figure who had hypertension combined with cardiac insufficiency.

After taking 3 types of antihypertensive agents orally, his blood pressure did not reach the goal, which met the diagnostic criteria for resistant hypertension. The patient had RDN indications and was strongly willing to receive surgery; therefore, RDN was performed on February $3^{\text {rd }}$, 2012. After operation, the patient received perindopril $4 \mathrm{mg} /$ day and amlodipine $5 \mathrm{mg} /$ day to reduce blood pressure, and his blood pressure was controlled between 112-126/80-86mmHg. Strict follow-up was conducted after the surgery; the patient did not have obvious dyspnea and had an increased exercise tolerance compared to before the operation. The routine urine tests and renal function tests conducted on August $16^{\text {th }}, 2012$ were all normal, indicating that the surgery did not affect renal functions. The renal artery imaging re-examination showed no renal arterial stenosis (Figure 2). A urine tests and renal function tests every 12-month during the 6 years of follow-up is mandatory. The BP and creatinine CCr result as show in (Figure 3). There were no significant changes in SBP, DBP, and CCr after RDN in the long follow-up period.
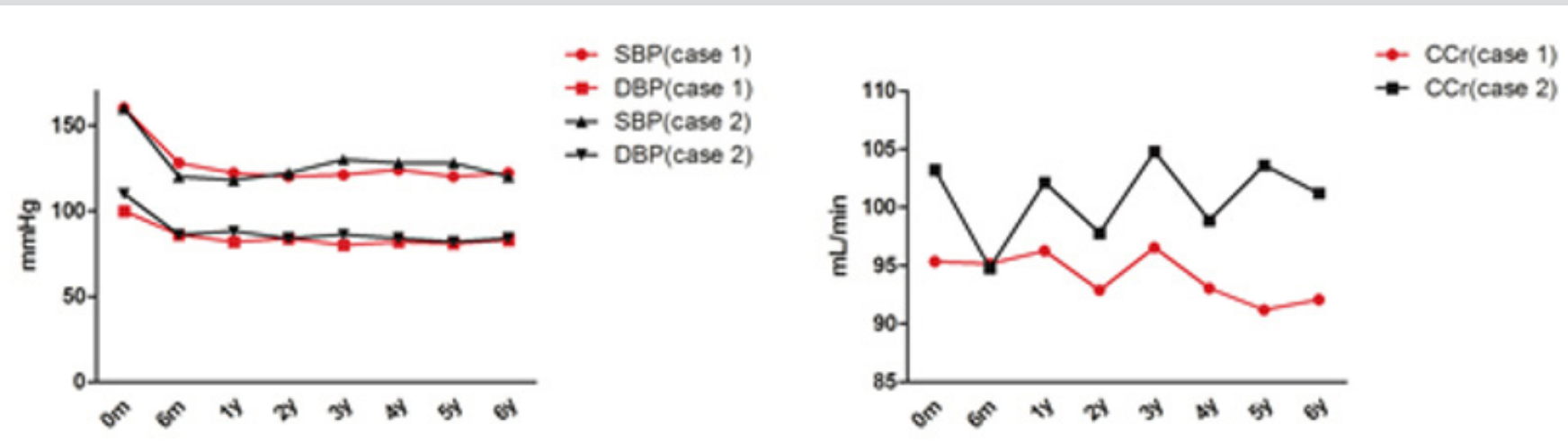

Figure 3: Changes in SBP, DBP, and CCr in case 1 and case 2 before RDN, 6-month(m) and 1,2,3,4,5 and 6-year(y) follow-up. 


\section{Discussion}

The American Heart Association published a scientific statement in 2008 to define resistant hypertension as the situation where, after lifestyle improvement, the systolic pressure and diastolic pressure require the concurrent use of 3 antihypertensive agents of different classes (one is a diuretic agent) or at least 4 agents to be controlled at the goal levels $(<140 / 90 \mathrm{mmHg}$ ) [7]. Currently, it is considered that the development of hypertension is multifactorial. The importance of the sympathetic nerve in influencing hypertension was understood early; therefore, sympathy-splanchnicectomy (including the renal sympathetic nerve) was invented to treat resistant hypertension. However, although this treatment technique achieved very good blood pressure control, it was not promoted due to severe adverse reactions [3]. Because of the rapid development of catheter-based radiofrequency ablation technology and the influence of the renal sympathetic nerve on blood pressure, Krum et al. [3] tested the idea of treating hypertension using RDN in the human body and obtained positive anti-hypertensive efficacy. In a series of HTN $[4,5]$ studies and recently published syudies [8,9], RDN has been shown to have excellent safety, and $97.0 \%$ of patients were free of manipulation-related complications.

No RDN-related renal arterial stenosis, aneurysm, or artery dissection was found during the follow up period. There was no death in the Simplicity HTN-1group. There were two deaths in the Simplicity HTN-2 group, which were not related to RDN itself. Two patients in HTN-2 had a glomerular filtration rate decreased by over $25 \%$, as did 3 patients in the control group; the difference between these two groups did not reach statistical significance. However, In the Simplicity HTN-3 trial [6], results observed 6-month post-surgery did not show effective BP reduction in resistant hypertension, which may be explained, at least in part, heterogeneity of the population (may be less effect in the AfricanAmerican population versus others), by Medtronic developed the new surgical learning curve, short follow-up period. Our preliminary experience indicated that RDN can play an important role in longer term BP regulation (at least 6 years) in refractory hypertension, and this new technology also had good safety in Chinese people. Our finding suggests that continued study into RDN for the treatment of resistance hypertension is of interest.

\section{ISSN: 2574-1241}

DOI: 10.26717/BJSTR.2019.15.002737

Guoping Yang. Biomed J Sci \& Tech Res

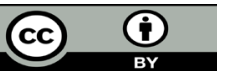

This work is licensed under Creative

Commons Attribution 4.0 License

Submission Link: https://biomedres.us/submit-manuscript.php

\section{References}

1. Di Bona GF, Kopp UC (1997) Neural control of renal function. Physiol Rev 77: 75-197.

2. Mahfoud F, Ukena C, Schmieder RE, Cremers B, Rump LC et al. (2013) Ambulatory blood pressure changes after renal sympathetic denervation in patients with resistant hypertension. Circulation 128(2): 132-140.

3. Krum H, Schlaich M, Whitbourn R, Sobotka PA, Sadowski J, et al. (2009) Catheter-based renal sympathetic denervation for resistant hypertension: a multicentre safety and proof-of-principle cohort study. Lancet 373(9671): 1275-1281.

4. Krum H, Schlaich MP, Sobotka PA, Böhm M, Mahfoud F et al. (2014) Percutaneous renal denervation in patients with treatment-resistant hypertension: final 3-year report of the Symplicity HTN-1 study. Lancet 383(9917): 622-629.

5. Esler MD, Bohm M, Sievert H, Rump CL, Schmieder RE et al. (2014) Catheter-based renal denervation for treatment of patients with treatment-resistant hypertension: 36 month results from the SYMPLICITY HTN-2 randomized clinical trial. European heart journal 35(26): 1752-1759.

6. Bakris GL, Townsend RR, Liu M, Cohen SA, D’Agostino R, et al. (2014) Impact of renal denervation on 24-hour ambulatory blood pressure: results from SYMPLICITY HTN-3. Journal of the American College of Cardiology 64(11): 1071-1078.

7. Calhoun DA, Jones D, Textor S, Goff DC, Murphy TP, et al. (2008) Resistant hypertension: diagnosis, evaluation, and treatment: a scientific statement from the American Heart Association Professional Education Committee of the Council for High Blood Pressure Research. Circulation 117(25): e510-526.

8. Townsend RR, Mahfoud F, Kandzari DE, Kario K, Pocock S, et al. (2017) Catheter-based renal denervation in patients with uncontrolled hypertension in the absence of antihypertensive medications (SPYRAL HTN-OFF MED): a randomised, sham-controlled, proof-of-concept trial. The Lancet 390(10108): 2160-2170.

9. Kiuchi MG, Graciano ML, Carreira MA, Kiuchi T, Chen S, et al. (2016) Long-Term Effects of Renal Sympathetic Denervation on Hypertensive Patients with Mild to Moderate Chronic Kidney Disease. Journal of clinical hypertension 18(3): 190-196.

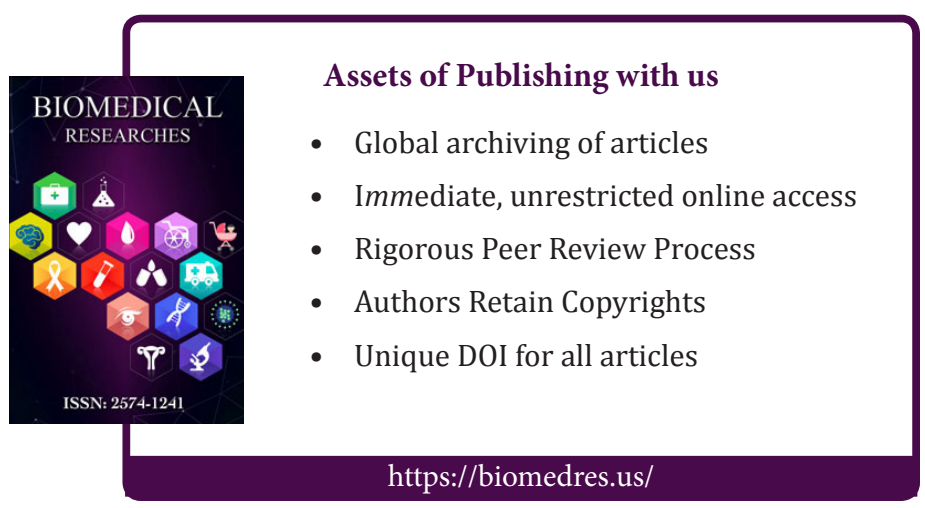

Copyright@ Guoping Yang | Biomed J Sci \& Tech Res| BJSTR. MS.ID.002737. 